
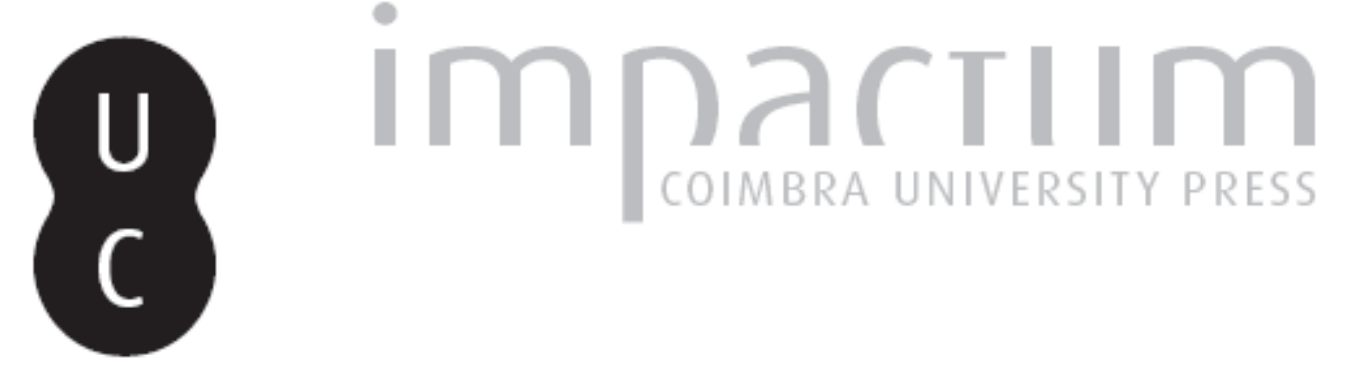

\title{
[Recensão a] AGNIESZKA KOTLIÑSKA-TOMA (2015), Hellenistic Tragedy. Texts, Translations and a Critical Survey
}
Autor(es):
Rodrigues, Nuno Simões
Publicado por: Centro de História da Universidade de Lisboa
URL persistente:
URI:http://hdl.handle.net/10316.2/41171
DOI:
DOI:https://doi.org/10.14195/0871-9527_25_23

Accessed : $\quad$ 26-Apr-2023 06:41:41

A navegação consulta e descarregamento dos títulos inseridos nas Bibliotecas Digitais UC Digitalis, UC Pombalina e UC Impactum, pressupõem a aceitação plena e sem reservas dos Termos e Condições de Uso destas Bibliotecas Digitais, disponíveis em https://digitalis.uc.pt/pt-pt/termos.

Conforme exposto nos referidos Termos e Condições de Uso, o descarregamento de títulos de acesso restrito requer uma licença válida de autorização devendo o utilizador aceder ao(s) documento(s) a partir de um endereço de IP da instituição detentora da supramencionada licença.

Ao utilizador é apenas permitido o descarregamento para uso pessoal, pelo que o emprego do(s) título(s) descarregado(s) para outro fim, designadamente comercial, carece de autorização do respetivo autor ou editor da obra.

Na medida em que todas as obras da UC Digitalis se encontram protegidas pelo Código do Direito de Autor e Direitos Conexos e demais legislação aplicável, toda a cópia, parcial ou total, deste documento, nos casos em que é legalmente admitida, deverá conter ou fazer-se acompanhar por este aviso.

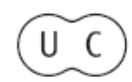



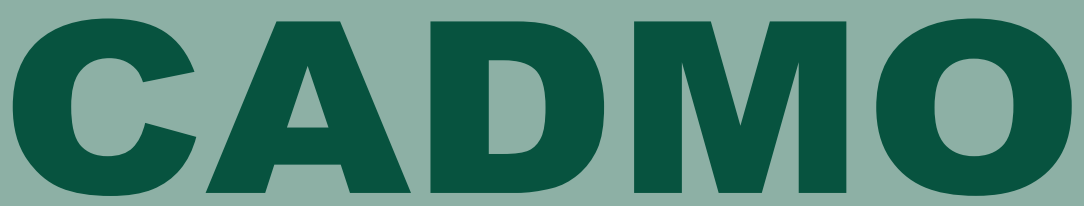

Revista de História Antiga

\author{
Centro de História \\ da Universidade de Lisboa
}

\title{
25
}

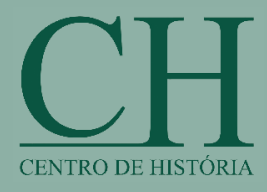

47人

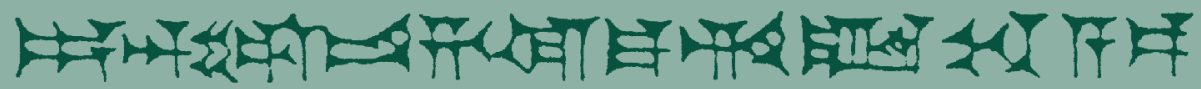

MHNIN AEI $\triangle \mathrm{E} \Theta \mathrm{EA} \Pi \mathrm{\Pi H} \Lambda \mathrm{HIA} \Delta \mathrm{E} \Omega$ 
vam para si como filhas (D. 59.119). Num capítulo que pretende dar ênfase à relação mãe-filha, Mothers and Daughters in a Family Business, seria mais lógico ter desenvolvido a ligação de Neera e de Fano, ou mostrado como a influência de outros indivíduos é fundamental para a construção do ser adulto e do exercício de uma profissão.

Contudo, no sétimo capítulo, The Costs and Rewards of Sexual Services, é destacada a figura de Nicareta, como fornecedora de prazeres associados a parafilias, facto que teria particular importância para a rede comercial em que estaria inserida, uma vez que aumentava os preços dos serviços prestados (p. 168).

Ao longo deste amplo estudo é curioso verificarmos a teoria de Edward Cohen em relação às leis de protecção daqueles que exerciam a prostituição. $O$ autor defende que, pese embora alguma controvérsia entre os académicos, a lei podia proteger aqueles que eram alvo de exploração sexual por parte de terceiros, não só pessoas livres, como também escravos, o que o leva a abordar o conceito de hybris, a sua utilização no campo jurídico e qual a sua relação com a vitimização do corpo.

Athenian Prostitution: The Business of Sex preenche uma lacuna existente nos estudos sociais da Antiguidade, designadamente no domínio dos estudos sobre quem exercia o labor da prostituição, na sociedade antiga ateniense. Edward Cohen explora, assim, não só o lado óbvio da prostituição, como também vai mais além, inovando e tornando-se um apoio bibliográfico nos futuros estudos sobre o tema.

Joana Pinto Salvador Costa

Universidade de Lisboa, Centro de História

AGNIESZKA KOTLIŃSKA-TOMA (2015), Hellenistic Tragedy. Texts, Translations and a Critical Survey. London, Bloomsbury Academic, 322 pp. ISBN 9781472524218.

Diz a A. no prefácio da obra em recensão que «this book has been written to fill a rather conspicuous gap in the study of the history of ancient drama». Com efeito, em boa hora o fez e, parece-nos, com um saldo altamente positivo. Se o período helenístico, como ela própria nota, é o tempo sobretudo da emergência de um novo tipo de comédia, a Comédia Nova, isso não significa que não tenham existido outros géneros, igualmente importantes, mas que as vicissitudes do tempo e da história, por variadas razões, levaram a que ficassem de algum modo obscurecidos.

É precisamente isso que parece ter acontecido com a tragédia helenística. Já sabíamos que os tempos posteriores a Alexandre tinham também produzido as suas tragédias. Sabíamos inclusive que algumas delas terão tido particular 
importância e que um estilo e género poético que começou por ser essencialmente ateniense teria acabado por se difundir pelo mundo antigo com razoável eficácia. Se o sabíamos e o intuíamos antes, o livro de A. Kotlińska-Toma vem trazer argumentos suplementares para consolidarmos a percepção que tínhamos.

Além de dedicar um capítulo, da maior utilidade, aos tragediógrafos e às tragédias helenísticas, com o qual proporciona ao leitor uma perspectiva abrangente do corpus possível para o estudo desta matéria (não esqueçamos que conhecemos sobretudo matéria relativa ao período clássico), a A. tem ainda a preocupação de incluir no livro os fragmentos desses materiais, que nos chegaram, propondo ainda traduções para língua inglesa, o que os torna particularmente acessíveis a um espectro de leitores ainda mais alargado.

Os capítulos 1 e 4 abordam temas estruturais e formais da tragédia helenística, ficando-nos a percepção de que teria, talvez, sido útil fundir, ou pelo menos apresentar em seguimento, essas duas partes.

De particular destaque é o capítulo 3 , que se dedica à tragédia helenística de tema bíblico. Neste âmbito, é evidente que a famosa Exagoge de Ezequiel-o-Trágico assume um lugar de destaque. Tratando-se de um conjunto de fragmentos particularmente significativo e de uma produção feita num contexto cultural igualmente específico, o do judaísmo helenístico, a tragédia de Ezequiel sobre Moisés é um dos temas eventualmente mais estudados neste domínio. Kotlińska-Toma não é excepção, retomando-o e conferindo-lhe a atenção que ele de facto merece. Sabemos que a cultura judaica helenística terá produzido outras tragédias, como a Susana de Nicolau Damasceno. Mas não há, para este caso, informação disponível como a que temos para o exemplo de Ezequiel. Estudos anteriores, como os de Jacobson (1983), Holladay (1989) e Lanfranchi (2006), vêm-se agora renovados pela investigação e proposta de nova tradução de Kotlińska-Toma.

Aquele que é talvez o mérito maior desta publicação, além da apresentação dos fragmentos de tragédias helenísticas de que temos conhecimento, com respectivas propostas de tradução em língua inglesa, é precisamente o de mostrar que o género trágico grego não morreu de facto no século $V$ a.C. É evidente que as suas importância e função alteraram-se, ao sabor das conjunturas históricas, mas o género em si manteve-se, com provas dadas, e criando um elo de continuidade para o que sabermos ter sido depois a tragédia romana.

Praticamente desde o estudo de P. Venini («Note sulla tragedia ellenistica», Dioniso 16, 1953, 3-26) não havia uma investigação tão aprofundada e com tanta qualidade científica como o que agora temos à nossa disposição por meio da Bloomsbury. A versão inglesa do trabalho de A. Kotlińska-Toma, Professora da Universidade de Wrocław, possibilita o seu acesso a um público mais lato, o que só podemos louvar.

Nuno Simões Rodrigues Universidade de Lisboa, Centro de História 